\title{
TELETRABALHO E SUAS COMPLEXIDADES
}

\author{
https://dx.doi.org/10.48097/2674-8673.2021n5p17
}

Wellington Cosme da Silva ${ }^{1}$

Camila Ferreira Lima de Albuquerque Brito ${ }^{2}$

\section{RESUMO}

Opresente artigo tem como objetivo estudar a modalidade de trabalho a distância, o teletrabalho, no atual cenário mundial, desenvolvido e controlado por meio do uso das tecnologias de informação e comunicação, abordando as principais temáticas, inclusive a diferença em relação ao trabalho em domicílio, sendo o teletrabalho uma forma de flexibilidade da atividade laboral que trouxe vantagem e desvantagem ao funcionário, em relação à jornada de trabalho. A intensão é refletir sobre o aprimoramento do regime de teletrabalho de forma a conciliar a produtividade e a saúde mental dos trabalhadores. A problemática em relação à flexibilização está relacionada à relação de emprego, ou seja, a aplicabilidade da jornada de trabalho e as horas extras e critérios de subordinação, com o advento da reforma trabalhista (Lei n. 13.467/2017), das regras sobre teletrabalho previstas na Consolidação das Leis Trabalhistas (CLT) e aquelas presentes na Medida Provisória $\mathrm{n}^{\circ}$ $927 / 20$, em função da calamidade pública, entendendo-se que devem ser preservados dois direitos sociais fundamentais: saúde e trabalho.

Palavras-chave: Teletrabalho. Relação de emprego. Jornada de trabalho. Pandemia. Reforma trabalhista.

Data de submissão: 20/01/2021

Data de aprovação: 18/03/2021

\begin{abstract}
This article aims to study the distance work modality, telework, in the current global scenario, developed and controlled through the use of information and communication technologies, addressing the main themes, including the difference in relation to homework, as teleworking is a form of flexibility in the work activity that brought advantages and disadvantages to the employee, in relation to the working day. The intention is to reflect on the improvement of the telework regime in order to reconcile workers' productivity and mental health. The problem in relation to flexibility is related to the employment relationship, that is, the applicability of working hours and overtime and subordination criteria, with the advent of the labor reform (Law n.13.467/2017), of the rules on telework foreseen in the Consolidation of Labor Laws (CLT) and those present in Provisional Measure $n^{\circ} 927 / 20$, due to the public calamity, understanding that two fundamental social rights must be preserved: health and work.
\end{abstract}

Keywords: Telework. Employment relationship. Working time. Pandemic. Labor reform.

\footnotetext{
${ }^{1}$ Graduando em Direito pela Faculdade Metropolitana da Grande Recife - FMGR.

E-mail: wellingtsilva@hotmail.com

${ }^{2}$ Advogada, mestranda e professora da Faculdade Metropolitana da Grande Recife, Faculdade de Ciências

Aplicada de Limoeiro - FACAL e Curso de Aplicação. E-mail: profa.camilalima@cursodeaplicacao.com.br
} 


\section{INTRODUÇÃO}

Este artigo tem como objetivo analisar os aspectos que cercam o teletrabalho, analisando suas particularidades, características, estrutura e validade, dentro do cenário atual.

A possibilidade de trabalhar em casa tem motivado muitos trabalhadores e empresas. É nítido que, no momento atual (período de pandemia), o número de colaboradores que não se veem obrigados a se deslocar de suas residências para a empresa e realizar as atividades laborais teve um aumento significativo.

Isso só é possível devido à evolução das tecnologias que têm alterado a realização de inúmeras atividades, cotidianas ou não, que dispensam o deslocamento físico do ser humano. Já no tocante ao teletrabalho, ou seja, trabalhar fora da empresa, esse tipo de atividade existe há bastante tempo. Todavia, o que há de diferente é a inclusão do uso de tecnologia, fazendo com que as atividades econômicas cada vez mais mantenham distância das tradicionais, ou seja, grupo de trabalhadores aglomerados. É perceptível que o teletrabalho apresenta vários termos, tais como: home office, trabalho remoto, trabalho a distância, etc. Estes profissionais fazem contatos com clientes, formam equipes de trabalho, realizam projetos e trocam informações sempre que necessário. Desta forma, o trabalhador poderá realizar algumas atividades a distância em qualquer lugar, reduzindo assim a distância existente entre trabalhador/empresa e seus clientes. Essas ferramentas são mais usadas na área de tecnologia, pois se trata de trabalho mais flexível, equilibrando a produtividade com a qualidade de vida (ROCHA, 2014). Haja vista que as grandes empresas buscam constantemente uma forma de aumentar a lucratividade e competitividade com seus concorrentes.

Com o advento da Lei 13.467/17, que alterou alguns artigos da Consolidação das Leis Trabalhistas (CLT), a mencionada lei também trouxe benefícios aos trabalhadores, tais como: otimização do tempo de deslocamento de ida e vinda ao trabalho; maior flexibilidade e autonomia de horários, visando à qualidade de vida, e assim, respeitando a dignidade da pessoa humana, conforme descreve a Constituição Federal; além da redução de despesas pelo empregador, entre outros.

Desde o período da Idade Média, com a criação das pequenas oficinas, sala do artesão, e mais tarde com o surgimento da Revolução Industrial, vieram as máquinas a vapor que trouxeram grande aumento da produção e assim mais agilidade. Segundo Martins (2014), as oficinas dos artesãos foram sendo substituídas pelas fábricas e as ferramentas foram sendo substituídas pelas máquinas. Logo, surgiram associações de trabalhadores e, consequentemente, as normas jurídicas relativas à proteção dos colaboradores. Surge, então, o Direito do Trabalho, reconhecido pelo Estado, que passou a regulamentar o direito individual 
do trabalho, com o intuito de proteger o trabalhador de práticas ilícitas por parte do empregador. (PASCHOAL, 2018, p. 27).

Dessa forma, a associação dos trabalhadores, na defesa dos seus direitos, teve grande influência no aparecimento no Direito Trabalhista, pois conforme cita Silva (2012) a ação dos trabalhadores reunidos em associações na defesa dos direitos comuns veio a constituir-se em uma das mais evidentes forças modeladoras do Direito do Trabalho, sendo o fator determinante para o seu surgimento como ciência jurídica.

No Brasil, com o advento da Consolidação das Leis Trabalhistas (CLT), houve várias proteções ao trabalhador. Entretanto, a evolução tecnológica trouxe novos formatos de trabalho, ou seja, a figura do teletrabalho. Este novo modelo de trabalho apresenta a busca de uma forma de atividade mais flexível.

\section{O TELETRABALHO}

O teletrabalho é uma espécie de trabalho que surgiu com o advento da tecnologia e, segundo Bomfim (2018, p. 133-135), é um trabalho à distância, realizado fora do estabelecimento do empregador. O teletrabalho pode ser desenvolvido no domicílio do empregado ou em um centro de computação, um escritório virtual ou alugado por hora para este fim.

No Brasil, por muito tempo, foram usados os termos telecentro ou centro satélite de telesserviço para se referir a teletrabalho. Ao longo dos tempos pairavam dúvidas em considerar ou não as tecnologias da informação e de comunicação como essenciais no teletrabalho, ou até mesmo se o teletrabalho era uma espécie de "trabalho a distância" ou "trabalho em domicílio". Não devemos afirmar que teletrabalho é apenas domiciliar, visto que não se limita ao domicílio, pois o lugar de trabalho neste formato se dá em qualquer ambiente acessível à rede mundial de computadores.

Logo, podemos verificar que o trabalho a distância se refere às espécies de teletrabalho e trabalho em domicílio. Neste sentido, o entendimento de Silveira e Silva (2004) é de que

o teletrabalho, sendo o trabalho exercido total ou parcialmente distante da empresa de forma telemática diferencia-se do trabalho em domicílio, já que este, em regra, acontece fora da empresa e sem contato pessoal com a mesma, e ainda, utiliza-se dos meios normais de comunicação como o telefone e fax, enquanto o teletrabalho é norteado por alta tecnologia. (SILVEIRA E SILVA, 2004, p. 102-109). 
A Organização Internacional do Trabalho (OIT) traz a definição de teletrabalho como qualquer trabalho feito distante dos escritórios/empresa, onde o trabalhador não mantem qualquer contato pessoal como seus colegas, mas a comunicação se faz por meio da tecnologia. O legislador, ao modificar o artigo $6^{\circ}$ da CLT, através da Lei $\mathrm{n}^{\circ} 12.551$ de 2011, escolheu o trabalho a distância de modo genérico.

\footnotetext{
Art. $6^{\circ}$ Não se distingue entre o trabalho realizado no estabelecimento do empregador, o executado no domicílio do empregado e o realizado a distância, desde que estejam caracterizados os pressupostos da relação de emprego.

Parágrafo único. Os meios telemáticos e informatizados de comando, controle e supervisão se equiparam, para fins de subordinação jurídica, aos meios pessoais e diretos de comando, controle e supervisão do trabalho alheio.
}

Nesse sentido, o legislador considera trabalho realizado por meios tecnológicos equiparando ao trabalho realizado presencialmente, todavia, deverá conter os requisitos da pessoalidade, a não eventualidade, a subordinação e a onerosidade, nos termos do parágrafo único do artigo $6^{\circ}$ e artigo $3^{\circ}$, ambos da CLT.

\section{Diferença entre teletrabalho e trabalho em domicílio}

O termo teletrabalho está relacionado ao trabalho remoto, por meio da tecnologia da informação e comunicação - TIC. É importante frisar que há atividades que têm maior identificação com o termo trabalho em domicílio do que teletrabalho. (HOLZMANN, 2011).

$\mathrm{O}$ trabalho remoto não está ligado diretamente à produção industrial, e sim ao uso de TIC, o qual teve o surgimento nos anos 1970, levando à noção de "trabalho a distância" e "trabalho em casa". O segundo termo, embora nos remeta à ideia de trabalho em domicílio, é uma premissa falsa, pois o trabalho em domicílio na maioria das vezes não é teletrabalho. Já o trabalho a distância compreende várias espécies, e uma delas é o teletrabalho, definido por Garcia (2017) como:

uma modalidade de trabalho a distância, típica dos tempos modernos, em que o avanço da tecnologia permite o labor preponderantemente fora do estabelecimento do empregador (normalmente na própria residência do empregado), embora mantendo o contato com este por meio de recursos. (GARCIA, 2017, p. 352$353)$.

Apesar das semelhanças, há que se destacar que o teletrabalho pode ser realizado em qualquer lugar, desde que longe do ambiente empresarial. Já o trabalho em domicílio está relacionado à moradia do empregado ou um lugar escolhido por ele. Ambos os termos estão ligados ao universo da organização do trabalho, referindo-se à atual tendência das atividades laborais sem que haja a necessidade de deslocamento do trabalhador ao local. 
Para facilitar o entendimento das diferenças acerca do trabalho à distância e do teletrabalho, destaca-se a citação de Delgado (2008):

O teletrabalho é realizado quando se utiliza de tecnologias que permitem que o trabalho seja feito fora do espaço da empresa. Porém, há um equívoco frequente que é comparar o teletrabalho ao trabalho em domicílio, visto que o teletrabalho não se limita ao domicílio. Assim, o lugar de trabalho hoje é, potencialmente, em qualquer ambiente onde a gestão de redes eletrônicas seja possível. (DELGADO, 2008, p. 234).

\section{Os tipos de teletrabalho}

As modalidades de teletrabalho são conceituadas por diversas maneiras pela Organização Internacional do Trabalho (OIT), em que se leva em consideração: a) local/ espaço de trabalho; b) horário/tempo de trabalho (integral ou parcial); c) tipo de contrato (assalariado ou independente); e d) competências requeridas (conteúdo do trabalho). Neste sentido, RUBENS VALTECIDES ALVES (2007) ressalta que

o teletrabalho abrange outros elementos, que não somente o domicílio do prestador de serviço. Com os recursos proporcionais pelos modernos sistemas de comunicação a distância, o teletrabalho pode ser exercido em qualquer local acordado pelos contratantes, ou seja, até locais virtuais onde, logicamente, não seja residência ou mesmo domicílio deles. (ALVES, 2007, p. 388).

De acordo com o artigo $6^{\circ}$ da CLT (Consolidação das Leis Trabalhistas), o teletrabalho em domicílio (home office) pode ser equiparado com o trabalho em domicílio normal. Todavia, o teletrabalho em domicílio é desenvolvido na residência do trabalhador, logo, é importante que a família se habitue a essa nova forma de trabalho e que haja um espaço específico para a realização desta modalidade. Assim, não deverá ser montado em área de circulação do restante da família (como a cozinha ou a mesa da sala de jantar). É notável que as ferramentas do trabalho flexível ou remoto, denominado teletrabalho, são de uso pessoal ou não, doados pelo empregador ou não.

\section{Aspectos jurídicos do teletrabalho}

A Constituição Federal de 1988 em seu artigo $7^{\circ}$, inciso XXVII, assegura a proteção do trabalhador em face da automação, na seguinte redação:

Art. $7^{\circ}$ São direitos dos trabalhadores urbanos e rurais, além de outros que visem à melhoria de sua condição social: (...)

XXVII - proteção em face da automação, na forma da lei;

Assim sendo, o teletrabalho necessitava de uma norma que a regulamentasse. A primeira referência com trabalho a distância (teletrabalho) foi descrita na lei número 
12.551/2011, que altera o art. $6^{\circ}$ da CLT, no qual equiparou o trabalho a distância ao trabalho realizado presencialmente:

Art. $6^{\circ}$ Não se distingue entre o trabalho realizado no estabelecimento do empregador, o executado no domicílio do empregado e o realizado a distância, desde que estejam caracterizados os pressupostos da relação de emprego.

Parágrafo único. Os meios telemáticos e informatizados de comando, controle e supervisão se equiparam, para fins de subordinação jurídica, aos meios pessoais e diretos de comando, controle e supervisão do trabalho alheio (BRASIL, 2011).

Com o advento da Lei $\mathrm{n}^{\circ} 13.467 / 2017$, conhecida como reforma trabalhista, houve importantes alterações na Consolidação das Leis Trabalhistas e, consequentemente, no modo pelo qual o trabalho é realizado. Segundo Bomfim(2018), a Lei 13.467/2017 pacificou as controvérsias a respeito do conceito e direitos do teletrabalhador quando incluiu o artigo 75-B e seguintes da CLT, que determinam que:

Art. 75-B. Considera-se teletrabalho a prestação de serviços preponderantemente fora das dependências do empregador, com a utilização de tecnologias de informação e de comunicação que, por sua natureza, não se constituam como trabalho externo.

Parágrafo único. O comparecimento às dependências do empregador para a realização de atividades específicas que exijam a presença do empregado no estabelecimento não descaracteriza o regime de teletrabalho.

Embora a lei 12.551/2011 tenha dado relevância ao teletrabalho, com a reforma trabalhista veio o reconhecimento dessa modalidade laboral. É certo que mesmo com alteração do artigo $6^{\circ}$ da CLT, não foi suficiente para suprir as lacunas relacionadas ao teletrabalho, de modo que só foi possível sanar de maneira clara e objetiva as dúvidas com o surgimento da reforma trabalhista. Assim, o conceito de teletrabalho está agora estampado no artigo 75-B da CLT.

Outra característica específica do teletrabalho é em relação ao contrato. O empregador poderá alterar o regime do contrato de trabalho de presencial para teletrabalho somente com anuência do empregado, por meio de aditivo contratual, e poderá alterar de regime de teletrabalho para presencial sem anuência do empregado, também por meio de aditivo contratual, mas deverá conceder um prazo de 15 dias de adaptação, conforme art. 75-C e seus parágrafos.

Todavia, a responsabilidade pela aquisição, manutenção e fornecimento dos equipamentos para que o trabalho remoto seja desenvolvido, bem como os custos com a infraestrutura, serão de responsabilidade do empregador. Assim, os bens econômicos disponibilizados pelo empregador para a realização do trabalho não serão considerados salário utilidade, conforme artigo 75-D. 
Segundo Caetano (2019), é do empregador a responsabilidade de instruir os empregados sobre a prevenção de acidentes ou doenças do trabalho, e o empregador deverá assinar termo de responsabilidade escrito, confirmando que recebeu as instruções, a fim de evitar eventual acidente ou doença do trabalho, conforme artigo 75-E e seu parágrafo único.

\section{RELAÇÃO DE EMPREGO}

As leis trabalhistas são voltadas para a proteção do trabalhador subordinado, entretanto, o teletrabalho pode ser de caráter autônomo ou subordinado. Vale destacar que o teletrabalho autônomo é aquele que presta serviços sem vínculo de subordinação, ou seja, não tem obrigação ao controle do empregador. Sendo assim, é o responsável pelas atividades e assume os riscos do negócio. Já o trabalhador subordinado é aquele que trabalha de forma não eventual, sob dependência do empregador, do qual recebe uma remuneração.

Autores como Dutra e Villatore (2014) afirmam que a subordinação se encontra presente na relação de teletrabalho. O legislador, ao modificar o parágrafo único do artigo $6^{\circ}$ da CLT, através da lei $\mathrm{n}^{\mathrm{o}} 12.551$, de 2011, aplicou o critério da subordinação, ao citar que "os meios telemáticos e informatizados de comando, controle e supervisão se equiparam, para fins de subordinação jurídica, aos meios pessoais e diretos de comando, controle e supervisão do trabalho alheio". Todavia, estão presentes requisitos da pessoalidade, não eventualidade, subordinação e onerosidade. Em seu artigo 3ㄹ caput, a CLT dispõe: “considera-se empregada toda pessoa física que prestar serviços de natureza não eventual ao empregador, sob a dependência deste, e mediante salário". No artigo $2^{\circ}$, caput, por outro lado, determina: "considera-se empregadora a empresa, individual ou coletiva, que, assumindo os riscos da atividade econômica, admite, assalaria e dirige a prestação pessoal de serviços".

\section{Da subordinação}

$\mathrm{Na}$ relação de emprego há que se observar alguns critérios, entre eles o da subordinação, descrito nos arts. $2^{\circ}$ e $3^{\circ}$ da CLT e no parágrafo único do artigo $6^{\circ}$ da CLT. De acordo com Jardim (2004, p. 59), o critério para verificar sua natureza jurídica tem como centro a existência ou não da subordinação e da avaliação dos casos concretos. Para a jurista Vera Winter (2005, p. 57), deve-se observar a forma como vai realizar a atividade laboral, podendo ser tanto de natureza comercial quanto civil ou trabalhista. Schwarz (2007) afirma que de todos os elementos qualificadores de uma efetiva relação de emprego, a subordinação é a mais evidente manifestação de vínculo existente entre o empregado e o empregador. 
Assim, os teletrabalhadores permanentes ou temporais ficam grande parte do tempo, se não integralmente, sob a supervisão direta ou indireta de seu superior. Ainda que o empregador não esteja no mesmo espaço físico que o funcionário, o mesmo responde diretamente ao seu subordinado. Deste modo, o parágrafo único da lei ${ }^{\circ} 12.551 / 11$, ao citar, especificamente, o uso de meios viabilizadores do teletrabalho, deve levar em consideração os principais níveis de subordinação, conforme Jardim (2004, p. 64):

a) Subordinação hierárquica. Nasce com o contrato de trabalho, apresentando relação de subordinação, ou seja, hierarquia entre empregado e empregador;

b) Subordinação econômica. Predomina o recebimento da remuneração do empregado;

c) Subordinação técnica. O empregado depende de equipamentos ou do sistema do empregador, principalmente quando se trata de teletrabalho;

d) Subordinação jurídica. O empregado fica sujeito às ordens e direção do empregador.

Neste contexto, o empregado em teletrabalho apresenta todas as características da subordinação, pois o mesmo está, de forma contínua, ligada à empresa, por meio de uma ligação online ao computador, permitindo que o empregador o fiscalize, mesmo não estando presente no interior da empresa. Logo, não há em que se falar da não subordinação, pois mesmo fora do ambiente empresarial os requisitos dos artigos $2^{\circ}$ e $3^{\circ}$ da CLT continuam presente e sobre fiscalização e algumas situações têm maior controle por parte do empregador.

\section{Controle da jornada}

A reforma trabalhista trouxe algumas mudanças benéficas a essa modalidade de trabalho, entretanto, afastou a jornada de trabalho no que se refere ao art. 62, III da CLT quando cita que os empregados em regime de teletrabalho não são abrangidos pelo regime previsto neste capítulo.

Para Bomfim (2018), essa alteração no inciso III do art. 62 da CLT é maléfica ao trabalhador. Primeiramente, observa-se que o mencionado artigo equiparou o teletrabalho como atividade incompatível com a fixação de horário de trabalho e com os gerentes, passando a abarcar os empregados em regime de teletrabalho, pois, tais profissionais terão flexibilidade para realizar suas atividades como bem entenderem, com a justificativa que no teletrabalho existe impossibilidade de controle da jornada laboral. 
Em contrapartida, Ravagnani e Rodrigues (2018) destacam que a mensuração da jornada de trabalho enfrenta obstáculos em decorrência de elementos intrínsecos à essência do teletrabalho, quais sejam: a autonomia e a flexibilidade de horário para execução das atividades. Sendo assim, ainda que reconhecida a subordinação do teletrabalhador, tal elemento não atrairia absolutamente todos os aspectos de uma relação de emprego tradicional, haja vista as peculiaridades inerentes à forma como o serviço é prestado.

Todavia, no que diz respeito ao direito do teletrabalhador, a perceber o pagamento de horas extras quando sujeitas à sobrejornada, os autores reconhecem que a limitação constitucional de horas a serem trabalhadas não pode cair no esquecimento.

Neste sentido, Delgado (2017) indica que a regra instituída a partir do artigo 62, III, trata de presunção relativa, isto é, que o empregado, na medida em que presta serviços na modalidade de teletrabalho, está exercendo atividade incompatível com o controle de jornada e, consequentemente, o empregador se vê isento da realização do referido controle. Logo, a interpretação do artigo 62, III, deve ser feita tão somente nos casos em que não há fiscalização do teletrabalhador. (MAGALHÃES, 2017, p. 294).

\section{Vantagens e desvantagen $s$ do teletrabalho}

O teletrabalho é uma nova modalidade de trabalho no cenário atual, sendo que, de princípio, podemos pontuar algumas vantagens e desvantagens. Uma das principais vantagens diz respeito à flexibilização de horário e local de trabalho; à organização do tempo, de modo a melhor conciliar demandas sociais, familiares, laborais e de lazer; à economia de tempo com transporte casa-trabalho, evitando gasto com combustível, uso do precário serviço de transporte coletivo, diminuindo riscos no trânsito e até assaltos; além da autonomia para organização do modo de trabalhar, principalmente no que diz respeito ao espaço e ao tempo. Toda essa flexibilização só é possível devido ao surgimento das novas tecnologias, o que traz mudanças na sociedade, relativas ao tempo de emprego.

Santos \& Miranda (2017) demonstram o aumento de cursos na modalidade a distância, onde os professores passam a ser divididos em conteudistas e tutores virtuais. Nesse ponto, é importante destacar o teletrabalho, especificamente, na modalidade em domicílio.

Destacam-se também as vantagens para as empresas: redução de custos operacionais e logísticos; redução de custos com espaço físico, equipamentos e manutenção; aumento da produtividade dos trabalhadores; redução da falta/atraso do colaborador; retenção de talentos em regiões e até países diversos, aumentando a presença das organizações em pontos 
diferenciados; redução de riscos ao meio ambiente, pois, com menos poluição, beneficia toda a sociedade.

Todavia, como o teletrabalho proporciona benefícios, também acarreta algumas desvantagens para os próprios teletrabalhadores: a falta de contato direto com os colegas na troca de ideias e compartilhamento das dificuldades; transferência de valores e da cultura organizacional; custos para a implantação e manutenção do sistema de teletrabalho; maior isolamento do trabalhador; redução da subordinação; enfraquecimento da representação e ação sindical. (VALENTIM, 2000, p. 58-62).

Estas vantagens e desvantagens têm de ser analisadas antes da adoção desta relação, tanto por parte dos empregados quanto pelos empregadores.

\section{O TELETRABALHO EM TEMPOS DE PANDEMIA}

A Lei $n^{\circ} 13.467 / 2017$ (reforma trabalhista) especificou o tema do teletrabalho, trazida de forma genérica pelo artigo $6^{\circ}$ da Consolidação das Leis do Trabalho - CLT entre o trabalho a distância e o trabalho presencial. Há, ainda, os artigos 62, III e 611-A, VIII. O primeiro, para localizar o teletrabalho entre as formas de prestação de serviço subordinado, excluído do controle da duração de jornada; e o segundo, para citá-lo como tema factível de negociação coletiva. Até o decreto de calamidade, tinha-se o contrato de teletrabalho como um pacto especial e formal e requisito constante no art. $75-\mathrm{C}$ da CLT. Com o advento da Covid-19, foi publicada a lei $\mathrm{n}^{\mathrm{o}} 13.979 / 20$, que dispõe sobre as medidas para o enfrentamento da pandemia. Em relação ao Direito do Trabalho, as principais Medidas Provisórias editadas foram a 927, de 22 de março de 2020 e a 936, de 01 de abril de 2020.

Com a Medida Provisória (MP) houve uma maior flexibilização para a adoção do teletrabalho, pois poderá ser realizada a critério do empregador, independente de acordos individuais ou coletivos, sendo dispensado o registro prévio da alteração no contrato individual de trabalho, conforme o art. 4 da MP 927/20.

\footnotetext{
Art. $4^{\circ}$ Durante o estado de calamidade pública a que se refere o art. $1^{\circ}$, o empregador poderá, a seu critério, alterar o regime de trabalho presencial para o teletrabalho, o trabalho remoto ou outro tipo de trabalho a distância e determinar o retorno ao regime de trabalho presencial, independentemente da existência de acordos individuais ou coletivos, dispensado o registro prévio da alteração no contrato individual de trabalho.
}

Diante disso, a flexibilização da legislação permitiu que as organizações adotassem o teletrabalho durante o distanciamento social, causado pela pandemia da COVID-19. Todavia, a MP n 927/20 não teve o cuidado com a proteção e a saúde do trabalhador. Assim, aplica-se a regra geral constante do art. 75-E e parágrafo único da CLT. 
Outra problemática com o teletrabalho no regime de exceção decorrente da calamidade pública pela Covid-19 e normatizado pela MP n ${ }^{\circ}$ 927/20 decorre no artigo 62, inciso III, da CLT, em que se aplica ao teletrabalho o previsto na regra geral (arts.75-A a 75E, da CLT). Embora não fosse necessário, o $\S 1^{\circ}$, do art. $4^{\circ}$ da MP $N^{o} 927 / 20$, dispõe expressamente sobre a aplicação do art. 62, inciso III, da CLT. Assim, o empregado, em regime de teletrabalho em função da pandemia do coronavírus, não registrará horário e não terá direito ao adicional de horas extras. Conclui-se no sentido de que não há incompatibilidade entre as regras sobre teletrabalho previstas na CLT e aquelas presentes na Medida Provisória $n^{0}$ 927, já que, nesta, a questão maior a ser enfrentada é a escassez de tempo para formalizações em função da calamidade pública, entendendo-se que devem ser preservados dois direitos sociais fundamentais: saúde e trabalho.

\section{CONCLUSÃO}

A tecnologia está em constante desenvolvimento, e isso tem trazido maior avanço ao mercado de trabalho e, consequentemente, novas modalidades de oferta. Essa busca por novos mecanismos que flexibilize a atividade laboral fez surgir o teletrabalho. É certo que esta modalidade busca minimizar o espaço entre a empresa e seus colaboradores, de modo que também se aproxima do público alvo através do trabalho a distância.

Com o advento da Reforma Trabalhista veio a modalidade de teletrabalho na qual o empregado pode realizar a prestação de serviços a distância com uso de meios da tecnologia da informação e comunicação - TIC. O trabalhador foi se adaptando a essas mudanças, as quais trouxeram vantagens e desvantagens. Embora o foco seja o benefício para o trabalhador, destacamos também as vantagens para as empresas. Há também que se destacar a relação de subordinação, pois existe uma falsa autonomia, tendo em vista a presença dos requisitos para a configuração do vínculo empregatício dentro do teletrabalho, conforme o parágrafo único do artigo $6^{\circ}$ da CLT. Percebeu-se que a noção clássica (subordinação jurídica) não oferece respostas para alguns casos em que o teletrabalho é prestado. Nesses casos, aventou-se a possibilidade de utilização da ideia de subordinação estrutural, até porque a subordinação objetiva pode trazer algumas dificuldades.

Todavia, o teletrabalho ficou prejudicado com o acréscimo do inciso III ao artigo 62 da CLT, pois, desobriga do controle de jornada prevista no artigo 62, III. Entretanto, o estudo realizado mostra claramente o controle de jornada por meio de equipamentos eletrônicos, mesmo que o trabalho seja realizado à distância. Sobretudo, é preciso atentar à vulnerabilidade do teletrabalhador que necessita de maior proteção jurídica. 


\section{REFERÊNCIAS}

ALVES, Rubens Valtecides. Teletrabalho: um conceito complexo no Direito brasileiro. Revista do Curso de Direito da Universidade Federal de Uberlândia, Uberlândia, ano 10, 2007.

BOMFIM, Volia Cassar. Resumo de direito do trabalho. 6. ed., rev., atual. e ampl. São Paulo: Método, 2018.

BRASIL. Decreto-Lei $n^{\circ} 5.452$, de $1^{\circ}$ de maio de 1943. Aprova a Consolidação das Leis do Trabalho. Disponível em: http://www.planalto.gov.br/ccivil_03/DecretoLei/Del5452.htm. Acesso em: 28 nov. 2020.

BRASIL. Presidência da República - Casa Civil - Subchefia para Assuntos Jurídicos. Lei no 13.979 de 06 de fevereiro de 2020. Disponível em: http://www.planalto.gov.br/ccivil_03/_ato2019-2022/2020/Lei/L13979.htm. Acesso em: 20 dez. 2020.

BRASIL. Congresso Nacional. Medida Provisória $n^{\mathbf{0}} 927$ de 2020. Disponível em: https://www.congressonacional.leg.br/materias/medidas-provisorias/-/mpv/141145. Acesso em: 20 dez. 2020.

BRASIL. Presidência da República - Casa Civil - Subchefia para Assuntos Jurídicos. Medida Provisória no $\mathbf{9 3 6}$ de 2020. Disponível em: http://www.planalto.gov.br/ccivil_03/_Ato2019-2022/2020/Mpv/mpv936.htm. Acesso em: 20 dez. 2020.

Constituição da República Federativa do Brasil, de 5 de outubro de 1988. Disponívelem: http://www.planalto.gov.br/ccivil_03/constituicao/constituicao.htm. Acesso em : 28 nov. 2020.

Lei $\mathrm{n}^{\circ}$ 13.467/2017, de 13 de julho de 2017. Altera a Consolidação das Leis do Trabalho (CLT), a fim de adequar a legislação às novas relações de trabalho. Brasília, DF. Disponível em: http://www.planalto.gov.br/ccivil_03/_ato20152018/2017/lei/L13467.htm. Acesso em: 28 nov. 2020.

Lei $\mathrm{n}^{\circ} 12.551 / 2011$, de 15 de dezembro de 2011. Altera o art. $6^{\circ}$ da Consolidação das Leis do Trabalho (CLT) para equiparar os efeitos jurídicos da subordinação exercida por meios telemáticos e informatizados à exercida por meios pessoais e diretos. Brasília, DF. Disponível em: http://www.planalto.gov.br/ccivil_03/_Ato20112014/2011/Lei/L12551.htm. Acesso em: 28 nov. 2020

CAETANO, Douglas. Passe na $\mathrm{OAB} 2^{\mathrm{a}}$ fase: prática trabalhista. 3. ed. São Paulo: Saraiva, 2019.

DELGADO, Mauricio Godinho. Curso de direito do trabalho. $7^{\text {a }}$ edição. São Paulo: LTr, 2008.

DELGADO, Maurício Godinho; DELGADO, Gabriela Neves. A reforma trabalhista no Brasil: com os comentários à Lei n. 13.467/2017. São Paulo: LTr, 2017.

DUTRA, Silvia Regina Bandeira; VILLATORE, Marco Antônio César. Teletrabalho e direito à desconexão. Revista Eletrônica do Tribunal Regional do Paraná, v. 3, p. 142-149, 2014. Disponível em: http://bit.ly/2Gj7Ujf. Acesso em: 7 dez. 2020. 
GARCIA, Gustavo Filipe Barbosa. Curso de direito do trabalho. 11. ed. Rio de Janeiro: Forense, 2017.

HOLZMANN, L. Trabalho a domicílio. In: CATTANI, A. D.; HOLZMANN, L. (Orgs.). Dicionário de trabalho e tecnologia. Porto Alegre: Zouk, 2011. p. 437-440.

JARDIM, Carla Carrara da Silva. O teletrabalho e suas atuais modalidades. 1. ed. São Paulo: LTr, 2004.

MAGALHÃES, Joalvo. Teletrabalho. In: Reforma Trabalhista: o mundo do trabalho em suas mãos. Rio de Janeiro: Curso Ênfase, 2017.

MARTINS, Sergio Pinto. Direito processual do trabalho. 35. ed. São Paulo: Atlas, 2014.

ORGANIZAÇÃO INTERNACIONAL DO TRABALHO (OIT). Convenio sobre el trabajo a domicilio. (n. 177). Disponível em: http://www.ilo.org/dyn/normlex/es/f?p=NORM LEXPUB: $\quad$ 12100:0: $\quad$ NO:12100: P12100_INSTRUMENT_ID:312322: NO. Acesso em: 05 dez. 2020.

PASCHOAL, G. H. Elementos de direito do trabalho. Curitiba: Instituto Memória, 2018.

RAVAGNANI, Christopher Abreu; RODRIGUES, Raphae 1 Marcos Baccaro. Os impactos da novel reforma trabalhista no teletrabalho. Revista Juris UniToledo, Araçatuba, v. 03, n. 02, p. 03-23, abr./jun. 2018.

ROCHA, B. S. Home office: o ponto de equilíbrio entre a qualidade de vida e a produtividade. 2014. Trabalho de Conclusão de Curso. Cesuca Faculdade Inedi.

SANTOS, Michel Carlos Rocha; MIRANDA, Michelly Cardoso. A eficácia horizontal dos direitos fundamentais: a proteção à intimidade e vida privada no teletrabalho em face de era virtual. Revista de Direito do Trabalho: RDT, v. 43, n. 175, p. 95-115, mar. 2017.

SILVEIRA E SILVA, Frederico. O teletrabalho como novo meio de laborar e sua compatibilidade com o ordenamento jurídico brasileiro. R. CEJ, Brasília, n. 27, p. 102-109, out. /Dez. 2004.

SILVA, Paulo Antônio Maia. Direito do Trabalho / Paulo Antônio Maia e Silva, Markus Samuel Leite Norat. 2. ed. Ver. E atual. - Leme: CL EDIJUR, 2012.

SCHWARZ, Rodrigo Garcia. Direito do trabalho. Rio de Janeiro: Elsevier, 2007.

WINTER, Vera Regina Loureiro. Teletrabalho: uma forma alternativa de emprego. São Paulo: LTr, 2005.

VALENTIM, João Hilário. Teletrabalho e relações de trabalho. Revista do Ministério Público do Trabalho, Brasília, $\mathrm{N}^{\circ}$ 19, p. 58-62, 2000. REV. MPT — BRASÍLIA, ANO X $\mathrm{N}^{\mathrm{o}} 19$ - mar. 2000. 